\title{
Intestinal Stoma Leakage
}

National Cancer Institute

\section{Source}

National Cancer Institute. Intestinal Stoma Leakage. NCI Thesaurus. Code C78369.

Leakage of contents from the intestinal stoma. 